\title{
Social Class as a Moderator of Positive Characteristics and Subjective Well-being: A Test of Resilience Theory
}

\author{
Patrick K. Murphy ${ }^{1}$ (D) Blake A. Allan ${ }^{2}$ \\ Accepted: 30 December 2021 / Published online: 17 January 2022 \\ (c) The Author(s), under exclusive licence to Springer Nature Switzerland AG 2022
}

\begin{abstract}
The purpose of this study was to investigate certain positive characteristics (i.e., social resourcefulness, personal resourcefulness, optimism, and meaning in life) as protective factors for people from lower social class backgrounds. Resilience theory (Yates \& Masten, 2004) posits that certain positive characteristics may act as protective factors against vulnerability. We tested this theory with a sample of adults in the United States who completed an online survey. Results partially supported our hypotheses. Subjective social status (SSS) moderated the relations from social resourcefulness and personal resourcefulness to life satisfaction. Specifically, social resourcefulness was a stronger predictor of life satisfaction for individuals with lower SSS compared to higher SSS. These results suggest that social resourcefulness may act as a protective factor for individuals with lower SSS. Results also replicated past findings on the positive relationship between optimism, meaning in life, personal resourcefulness, and subjective well-being. Implications for helping professionals and researchers are discussed.
\end{abstract}

Keywords Subjective social status $\cdot$ Social resourcefulness $\cdot$ Personal resourcefulness $\cdot$ Optimism $\cdot$ Meaning in life $\cdot$ Subjective well-being

\section{Introduction}

Positive psychology is the scientific and applied endeavor to investigate and promote human flourishing. However, much of the research in positive psychology has investigated the strengths and positive experiences of majority groups (e.g., White,

Patrick K. Murphy

pkmurphy@purdue.edu

Blake A. Allan

ballan@uh.edu

1 College of Education, Purdue University, 100 N. University St, West Lafayette, IN 47907, USA

2 Department of Psychological, Health, and Learning Sciences, University of Houston, Farish Hall 405, 3657 Cullen Blvd, Houston, TX 77204, USA 
middle class, etc.) and cast them as universal (Christopher \& Howe, 2014), while paying little attention to how positive psychological phenomena vary within and between cultural contexts (see Pedrotti \& Edwards, 2017). This lack of context has inadvertently led to the maintenance of deficit models of many minority groups and may, in turn, reinforce their marginalization (Christopher \& Howe, 2014). Additionally, assumptions of universality prevent the field of positive psychology from fully recognizing the inherent complexity in conceptions of the good life.

One group that has been particularly underrepresented in the positive psychology literature are those who come from lower social class backgrounds. Despite calls for positive psychology to address issues related to social class (Pedrotti, 2013), few studies have examined positive phenomena in lower social class groups (Frankenhuis \& Nettle, 2020). This gap in the literature may unintentionally produce a discordant narrative about social class groups (e.g., those with higher social class have strengths and those at the bottom only deficits) and fail to challenge stereotypes about these groups (Bullock, 1995). Without this research, mental health professionals have little information to guide strengths-based interventions to promote wellbeing in this population. To address this limitation, we aimed to explore and identify protective factors for groups who identify as having lower subjective social status (SSS). Using resilience theory (Yates \& Masten, 2004) to form hypotheses, we specifically investigated whether certain positive characteristics had a differential relation to subjective well-being for different social class groups.

\subsection{Social Class}

Social class represents "an individual or group's relative position in an economicsocial-cultural hierarchy," and denotes "power, prestige, and control over resources" (Diemer et al., 2013). Social class has been operationalized by two primary wayssocioeconomic status (SES) and subjective social status (SSS; Diemer et al., 2013). Typically, SES refers to objective aspects of social class, including levels of income, educations, and occupational prestige (Diemer et al., 2013). Conversely, SSS is conceptualized as the subjective perception of one's social standing and economic culture (Adler et al., 2000; Liu et al., 2004).

In recent years, researchers have made important distinctions in the relation between social class and various life outcomes. One critical and consistent finding is that SSS is a more robust predictor of well-being and psychosocial vulnerability than objective measures of SES (Adler et al., 2000; Cundiff et al., 2013; Franzini \& Fernandez-Esquer, 2006; Garza et al., 2017; Ostrove et al., 2000; Singh-Manoux et al., 2003; Singh-Manoux et al., 2005). Although SES is clearly important, a person's subjective perception of their social status appears to have a unique and powerful influence on their health and life outcomes. Yu and Blader (2020) found status to be a consistent mediator in the relations among social class and subjective wellbeing across a series of five studies. Moreover, people experience poorer health and greater levels of distress when they feel deprived relative to others based on economic inequalities (Subramanyam et al., 2009; Yngwe et al., 2003). Other research has revealed that stress related to social class identity conflicts may exacerbate 
inflammation processes that impair immune functioning, which in turn lead poorer physical and mental health (Destin, 2019). There are likely multiple mechanisms that underlie the relations among social class, health, and well-being, and SSS appears to be a crucial piece of the puzzle.

\subsection{Resilience Theory}

Resilience is a positive phenomenon that has direct relevance to at-risk populations, including people in lower social classes (Okech et al., 2012). People from lower social classes tend to experience poor health and well-being (Adler et al., 1993; Lachman \& Weaver, 1998), higher rates of premature mortality (Shaw \& Smith, 2006), lower levels of academic (Sirin, 2005) and career achievement, less social mobility (Blustein, 2006; Ma et al., 2016), and report institutional and interpersonal subjugation (Lott \& Bullock, 2007). Although lower social class groups often experience elevated risk for negative life outcomes, resilience has been identified as an important strength for individuals and families from low-income backgrounds (Okech et al., 2012). Therefore, resilience may be a crucial positive phenomenon to explore for people who identify as having lower social class status.

Resilience broadly refers to positive adaptation in the face of adversity (Yates \& Masten, 2004), but is also a multifaceted construct that can exist within individuals (e.g., traits and strengths) and environments (e.g., positive schooling, family, and communities). Resilience has been conceptualized and measured by two broad approaches - as a process and as characteristics of an individual (Ayed et al., 2019). From the process approach, resilience is the presence of positive functioning and outcomes (e.g., a lack of physical health problems or mental illness, post-traumatic growth, subjective well-being) despite having experienced prolonged or acute adverse experiences (i.e., "immunity against adversity"; Ayed et al., 2019). From a trait perspective, resilience is having both personal (i.e., "traits, talents, skills, or interests"; Nicholson, 2014, p. 11) and social resources that a person can activate during times of hardship to protect themselves from experiencing negative outcomes (e.g., contributing to the community, having social support; Meyer \& Mueser, 2011).

One notable theory of resilience is resilience theory (Yates \& Masten, 2004). According to resilience theory, the dynamic interplay between positive and negative factors within a person and their environment influence positive adaptation, developmental outcomes, and well-being. At the individual level, resilience theory provides a distinction between personal resources that are beneficial independent of risk and those that are most consequential to the well-being of people who experience greater levels of vulnerability - the former are termed assets and the latter protective factors (Yates \& Masten, 2004). Specifically, resilience theory suggests that certain protective factors (e.g., hope) predict greater psychological well-being but that this effect is greater for vulnerable groups than those who are less vulnerable. This is because what may facilitate positive adaptation in a high risk context (e.g., active parental monitoring and restrictions in a dangerous neighborhood) may be detrimental to an individual's development in a lower risk environment (e.g., a safer neighborhood; 
Yates \& Masten, 2004). Thus, a protective factor gains its resilience quality only for individuals who experience higher levels of risk.

\subsection{Protective Factors for Lower Social Class Groups}

Because resilience processes and protective factors likely vary based on risk context (Yates \& Masten, 2004), it is crucial to establish which resources promote resilience for distinct social groups that experience different levels of vulnerability. Data suggest that both optimism and meaning in life are inversely related to negative affect (Andersson, 1996; Machell et al., 2015) and positively associated with life satisfaction (Bailey et al., 2007), coping (Reed, 2016), and psychological well-being (Zika $\&$ Chamberlain, 1992). Past research on protective factors in samples with high levels of financial strain have indicated that meaning-making and optimism can help buffer the negative effects of adversity (Hamby et al., 2018). Moreover, studies of low-income families suggest that a positive outlook on life can have positive effects for both parents and their adolescent children (Crosnoe et al., 2002). Having a sense of purpose and positive future orientation are probably beneficial for most people, but these personal qualities may have a greater impact on the well-being of people who identify as having lower SSS compared to higher SSS because they experience greater levels of risk and adversity. Thus, optimism and meaning in life may be protective factors for people in lower social classes.

Additionally, because groups among the lower social classes are often disadvantaged due to a lack of resources and various forms of capital (Liu, 2011), using the internal and external resources they do have may be essential to their livelihood. Past research on resilience has identified interpersonal strengths, social support, and selfregulation as essential protective factors (Hamby et al., 2018; Masten, 2007; Sabina $\&$ Banyard, 2015). Furthermore, lower social class groups may value interdependence and prioritize social bonds to help them meet their needs (Carey \& Markus, 2016). Accordingly, the tendency to access external resources (i.e., social resourcefulness) and to engage in self-control, problem-solving, and effective coping (i.e., personal resourcefulness) may be crucial to the well-being of individuals from lower social class backgrounds. Research on these forms of resourcefulness suggest that they are correlated with global quality of life indicators such as life satisfaction and psychological well-being (Zauszniewski, 2016). For this reason, social and personal resourcefulness may be protective factors that have unique relevance for individuals from lower social class backgrounds.

\subsection{The Present Study}

Consistent with theory (Yates \& Masten, 2004) and the previously reviewed research, the goal of the current study was to examine whether positive characteristics (i.e., optimism, meaning in life, social resourcefulness, and personal resourcefulness) differentially predicted subjective well-being for individuals from lower and higher social classes. We used a process approach to operationalizing resilience, wherein resilience is measured by the maintenance of subjective well-being. From 
a process approach, resilience has often been operationalized by external adaptation (e.g., graduating high school; Masten \& Obradović, 2006). In our study, we used internal adaptation as a marker of resilience because few studies have focused on positive internal processes related to the subjective well-being (SWB) for individuals in lower social classes. SWB is a widely used operationalization of happiness and refers to both cognitive and affective appraisals of one's quality of life (Diener, 2000). We predicted that SSS would moderate the relationship between positive characteristics and SWB (i.e., life satisfaction, positive emotions, and negative emotions), such that positive characteristics would more strongly predict subjective wellbeing for individuals that identified as having lower SSS compared to higher SSS.

\section{Method}

\subsection{Participants}

To test our hypotheses, we aimed to collect a sample of adults across the social class spectrum living in the United States $(N=388)$. Our sample was comprised of $48.5 \%$ $(n=188)$ women, $47.7 \%(n=185)$ men, and $3.9 \%(n=15)$ who did not specify their gender. The average age of our participants was 38.9 years, with a range of 19 to 65 $(S D=11.29)$. In terms of race and ethnicity, the sample was predominantly White/ European American (76.8\%; $n=298)$, followed by $8.0 \%(n=30)$ Black/African American, 6.4\% $(n=25)$ Asian/Asian American, $4.1 \%(n=16)$ Hispanic/Latino/a American, $1.8 \%(n=7)$ American Indian/Native American, $1.5 \%(n=6)$ Multiracial, and $0.3 \%(n=1)$ selected other. For education, $0.3 \%(n=1)$ had less than high school, $1.8 \%(n=7)$ had some high school, $9.3 \%(n=36)$ were high school graduates, $4.6 \%(n=18)$ attended trade/vocational school, $27.1 \%(n=105)$ with some college, $44.3 \%(n=172)$ held a college degree, and $12.6 \%(n=49)$ earned a professional degree. The mean and median income were $\$ 63,808$ and $\$ 80,000(S D=80,245.13)$, respectively. Participants reported a wide variety of occupations, but the most common were sales associates $(n=16 ; 4.1 \%)$, managers $(n=13 ; 3.4 \%)$, accountants $(n=11 ; 2.8 \%)$, homemakers $(n=8 ; 2.1 \%)$, and office managers $(n=7 ; 1.8 \%)$.

\subsection{Instruments}

\subsubsection{Subjective Social Class}

The MacArthur Scale of Subjective Social Status (Adler et al., 2000) was used to measure subjective perceptions of social class status. The scale uses a picture of a 10-rung ladder to help participants visualize the social class hierarchy. Participants are instructed to think of the ladder as society, with those at the top having the most money, education, and respected jobs, and those at the bottom having the least of those social status indicators. Participants responded by indicating where they believed they fall on the ladder relative to others in society, ranging from 1 (bottom rung) to 10 (top rung). This measure is the most widely-used measure of subjective 
social class in social science research and has been found to have good test-retest reliability (Operario et al., 2004) and produce valid data (Cundiff et al., 2013).

\subsection{Optimism}

To assess for levels of dispositional optimism, we used the Revised Life Orientation Test by Scheier et al. (1994). Participants responded to the 10-item measure by rating the extent to which they agree with a series of statements ranging from 1 (strongly disagree) to 5 (strongly agree). Sample items include: "Overall, I expect more good things to happen to me than bad," and "If something can go wrong for me, it will (reverse coded)." The scale is a popular metric of optimism, and past research has demonstrated it to have acceptable internal consistency $(\alpha=0.78)$ and test-retest reliability (i.e., test-retest correlations of $0.68,0.60,0.56$, and 0.79 at four separate time points; Scheier et al., 1994). As evidence of construct validity, the scale modestly correlated with theoretically similar constructs ranging from $r=-0.36$ to $r=0.54$ (Scheier et al., 1994). In the current study, the estimated internal consistency was $\alpha=0.87$.

\subsection{Resourcefulness}

Both personal and social resourcefulness were measured with the Resourcefulness Scale (Zauszniewski et al., 2006). The scale consists of 16 items that assess personal resourcefulness and 12 items that measure social resourcefulness. Participants rated each item on a 6-point Likert scale ranging from 1 (not like me at all) to 6 (very much like me). A sample item for personal resourcefulness is "When faced with a difficult problem, I try to approach its solution in a systematic way," and a sample item for social resourcefulness is "When it is hard for me to make a decision, I ask someone to help me think things through." The personal and social resourcefulness subscales have acceptable internal consistency ( $\alpha=0.83$ and $\alpha=0.79$, respectively), and moderately correlate with each other ( $r=0.41$; Zauszniewski et al., 2006). In the current study, the estimated internal consistency for the personal and social resourcefulness subscales were $\alpha=0.90$ and $\alpha=0.87$, respectively.

\subsection{Meaning in Life}

We used the meaning in life subscale of The Meaning in Life Questionnaire (Steger et al., 2006) to assess the presence of meaning in one's life. The meaning in life subscale contains five items (e.g., "I understand my life's meaning") and is rated on a 7-point Likert scale from 1 (absolutely untrue) to 7 (absolutely true). Steger et al. (2006) found the subscale to correlate with related constructs (depression, $r=-0.48$; joy, $r=0.49$; intrinsic religiosity, $r=0.30$ ). Additionally, the scale had good internal reliability ( $\alpha=0.86$; Steger et al., 2006). In the current study, the estimated internal consistency was $\alpha=0.90$. 


\subsection{Subjective Well-Being}

As defined by Diener (2000), we measured subjective well-being by assessing positive affect, negative affect, and life satisfaction. We administered the 12-item Scale of Positive and Negative Experience (SPANE; Diener et al., 2010) to measure affect. The scale is comprised of a list of six positive feeling words and six negative feeling words, and sample items include "good," "joyful," "unpleasant," and "afraid." Participants responded by rating how frequently they experience each on a 5-point Likert scale ranging from 1 (very rarely or never) to 5 (very often or always). Diener et al. (2010) found the scale to be reliable (alpha coefficients ranging from 0.76 to 0.87 ) and valid (i.e., subscales correlated with each other and other popular measures of emotion, $r=-0.60$ and $r=0.76$, respectively). In the current study, the estimated internal consistency for the positive emotions and negative emotions subscales were $\alpha=0.92$ and $\alpha=0.90$, respectively.

The 5-item Satisfaction with Life Scale (SWLS; Diener et al., 1985) was used to measure life satisfaction. Sample items include, "The conditions of my life are excellent" and "I am satisfied with my life," and were rated on a 7-point Likert scale from 1 (strongly disagree) to 7 (strongly agree). The scale has shown to correlate with other validated measures of subjective well-being $(r=0.51)$ and demonstrated good internal reliability ( $\alpha=0.87$; test-retest correlation of $r=0.82$; Diener et al., 1985). In the current study, the estimated internal consistency for the SWLS was $\alpha=0.89$.

\subsection{Procedure}

Participants joined the study via Amazon Mechanical Turk (MTurk). Past research has shown MTurk to be a reliable tool to collect quality data (Buhrmester et al., 2011; Sprouse, 2011). We posted a link to our survey to the MTurk website, which provided prospective participants with information about the study, informed consent, and information about compensation. Study participants had to be (a) 18 years of age and (b) reside in the United States. Participants were compensated 0.30 USD upon completion of the survey. The initial sample was comprised of 497 participants. However, 29 participants did not provide any data, 76 did not answer all validity items correctly, and two cases were identified as outliers (see below). We deleted these cases, and our final sample size was 388 . Of this sample, $386(99.5 \%)$ of participants had completed data, $1(0.3 \%)$ was missing data on 7 items, and $1(0.3 \%)$ was missing data on 16 items. 


\section{Results}

\subsection{Preliminary Analyses}

All study variables displayed adequate univariate normality, with values of skewness and kurtosis ranging from -0.50 to 0.32 and -0.62 to 0.84 , respectively. To assess for potential outliers, we used Hoaglin and Iglewicz's (1987) method and examined extreme cases where scores were greater than 3.5 standard deviations from the mean. All cases fell within these parameters except for two cases for personal resourcefulness, which we deleted. Because we had very low number of participants missing data $(n=2)$, we used pairwise deletion for all analyses. Given that people with higher levels of education were overrepresented in the sample, we ran the following analyses with levels of education as a covariate. The pattern of results was the same regardless of the covariate, so we report the following analyses without level of education. Finally, we conducted Harman's single factor test to evaluate issues with common methods bias. The forced single factor explained $28.86 \%$ of the variance, which is lower than the typical threshold of $50 \%$ indicating issues with common methods bias.

\subsection{Correlation Analyses}

Table 1 displays correlation and descriptive statistics for study variables. Subjective social class was significantly related to life satisfaction $(r=0.47, p<0.001)$, positive emotion $(r=0.38, p<0.001)$, and negative emotion $(r=-0.20, p<0.001)$. Additionally, life satisfaction was significantly related to personal resourcefulness $(r=0.33, p<0.001)$, social resourcefulness $(r=0.41, p<0.001)$, optimism $(r=0.57, p<0.001)$, and meaning in life $(r=0.65, p<0.001)$.

Table 1 Correlations and descriptive statistics for study variables

\begin{tabular}{|c|c|c|c|c|c|c|c|c|}
\hline & 1 & 2 & 3 & 4 & 5 & 6 & 7 & 8 \\
\hline 1. Social Class & - & & & & & & & \\
\hline 2. Optimism & $.35^{* *}$ & - & & & & & & \\
\hline 3. Personal Resourcefulness & $.16^{* *}$ & $.39 * *$ & - & & & & & \\
\hline 4. Social Resourcefulness & $.20 * *$ & $.17^{* *}$ & $.49 * *$ & - & & & & \\
\hline 5. Meaning in Life & $.27 * *$ & $.52 * *$ & $.45^{* *}$ & $.33 * *$ & - & & & \\
\hline 6. Life Satisfaction & $.47 * *$ & $.57 * *$ & $.33^{* *}$ & $.41 * *$ & $.65^{* *}$ & - & & \\
\hline 7. Positive Emotion & $.38 * *$ & $.63^{* *}$ & $.51 * *$ & $.41 * *$ & $.60 * *$ & $.71 * *$ & - & \\
\hline 8. Negative Emotion & $-.20 * *$ & $-.57 * *$ & $-.28 * *$ & -.10 & $-.42 * *$ & $-.48 * *$ & $-.60 * *$ & - \\
\hline$M$ & 5.06 & 19.76 & 67.44 & 43.00 & 23.81 & 21.96 & 21.15 & 13.78 \\
\hline$S D$ & 1.82 & 5.47 & 13.01 & 10.96 & 7.25 & 7.99 & 5.44 & 5.37 \\
\hline
\end{tabular}

Note: $* p<.05, * * p<.01$ 


\subsection{Regression Analyses}

We conducted hierarchical regression to test study hypotheses. In Step 1, we entered subjective social class, optimism, personal resourcefulness, social resourcefulness, and meaning in life. In Step 2, we entered the interaction terms, which were the products of subjective social class and each of the other predictor variables. To reduce multicollinearity, we used the $\mathrm{z}$-scores of each term to compute interaction variables.

Table 2 shows the hierarchical regression of study variables predicting life satisfaction. In Step 1, subjective social class, optimism, personal resourcefulness, social resourcefulness, and meaning in life significantly predicted life satisfaction, $F(5$, $380)=109.48, p<0.001, R^{2}=0.59$. In Step 2, the interaction terms were added, and only the interaction terms for personal and social resourcefulness significantly predicted life satisfaction, $F(9,376)=64.43, p<0.001, R^{2}=0.61$. Adding the interaction terms explained an additional $2 \%$ of the variance in life satisfaction.

Figures 1 and 2 display these significant interactions. We created three subjective social class groups to visualize the hypothesized relationships. Those whose scores were 0.5 standard deviations below the mean comprised the lower social class group, those whose scores were between -0.5 to 0.5 standard deviations from the mean comprised the middle social class group, and those whose scores were above 0.5 standard deviations from the mean comprised the upper social class group. As depicted in Fig. 1, all social class groups had a positive relation between social resourcefulness and life satisfaction. However, the relation between social resourcefulness and life satisfaction was stronger for the lower social class group compared

Table 2 Regression analysis examining subjective social class as a moderator of the relations between the positive characteristics and life satisfaction

\begin{tabular}{lcccccccccc}
\hline & $\beta$ & $B$ & $S E$ B & $t$ & $p$ & $d f$ & $R$ & $R^{2}$ & $R^{2} \Delta$ & $F$ \\
\hline Step 1 & & & & & $<.001$ & 5 & .77 & .59 & .59 & 109.48 \\
Social Class & .23 & 1.02 & .16 & 6.54 & $<.001$ & & & & & \\
Optimism & .28 & .40 & .60 & 6.76 & $<.001$ & & & & & \\
Personal Resourcefulness & -.12 & -.07 & .03 & -2.85 & .005 & & & & & \\
Social Resourcefulness & .24 & .17 & .03 & 6.15 & $<.001$ & & & & \\
Meaning in Life & .41 & .45 & .05 & 9.92 & $<.001$ & & & & & \\
Step 2 & & & & & $<.001$ & 9 & .78 & .61 & .02 & \multirow{2}{*}{64.43} \\
Social Class & -.52 & -2.26 & .88 & -2.57 & .010 & & & & \\
Optimism & .26 & .38 & .06 & 6.10 & $<.001$ & & & & & \\
Personal Resourcefulness & -.11 & -.07 & .03 & -2.59 & .010 & & & & & \\
Social Resourcefulness & .23 & .16 & .03 & 5.82 & $<.001$ & & & & \\
Meaning in Life & .40 & .44 & .05 & 9.40 & $<.001$ & & & & \\
SocialClassXOptimism & -.05 & -.35 & .31 & -1.13 & .258 & & & & & \\
SocialClassXPersonalResourceful & .77 & .09 & .02 & 3.81 & $<.001$ & & & & & \\
SocialClassXSocialResourceful & -.08 & -.67 & .34 & -1.96 & .050 & & & & & \\
SocialClassXMeaninginLife & -.06 & -.50 & .34 & -1.46 & .146 & & & & & \\
\hline
\end{tabular}




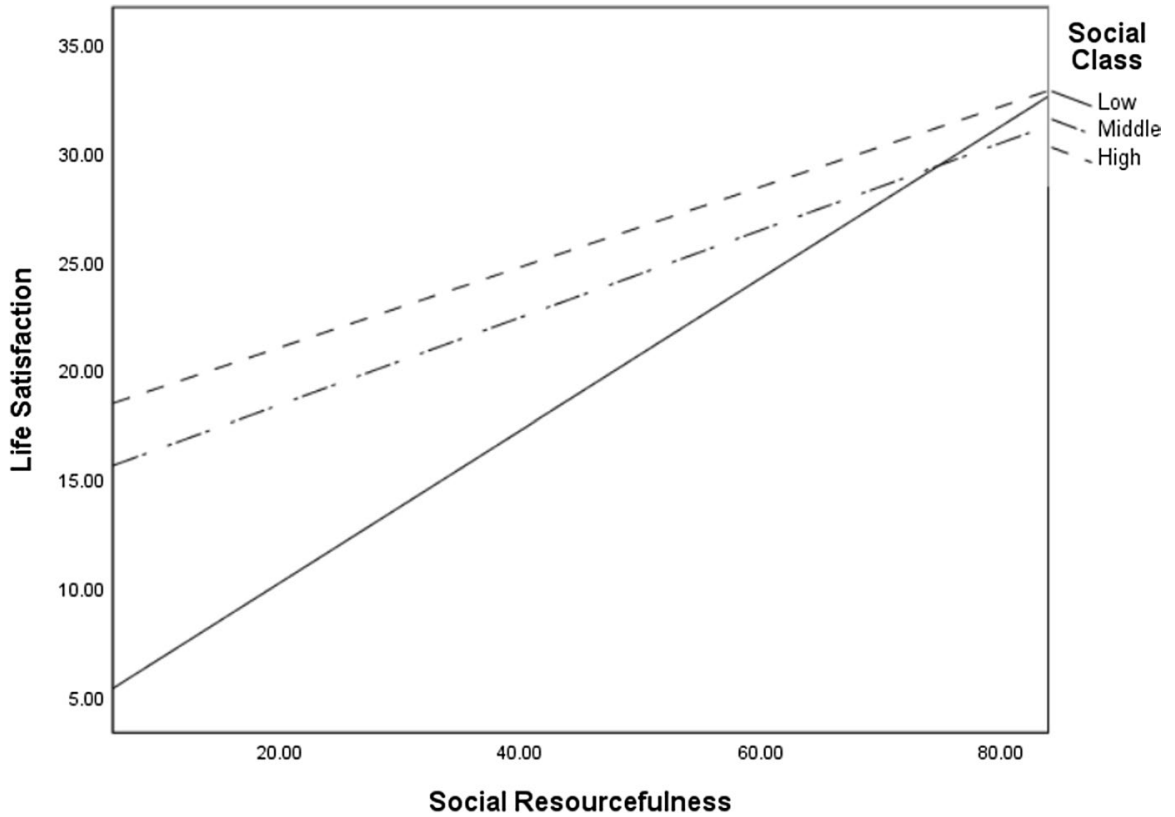

Fig. 1 Subjective social class as a moderator of the relation between social resourcefulness and life satisfaction

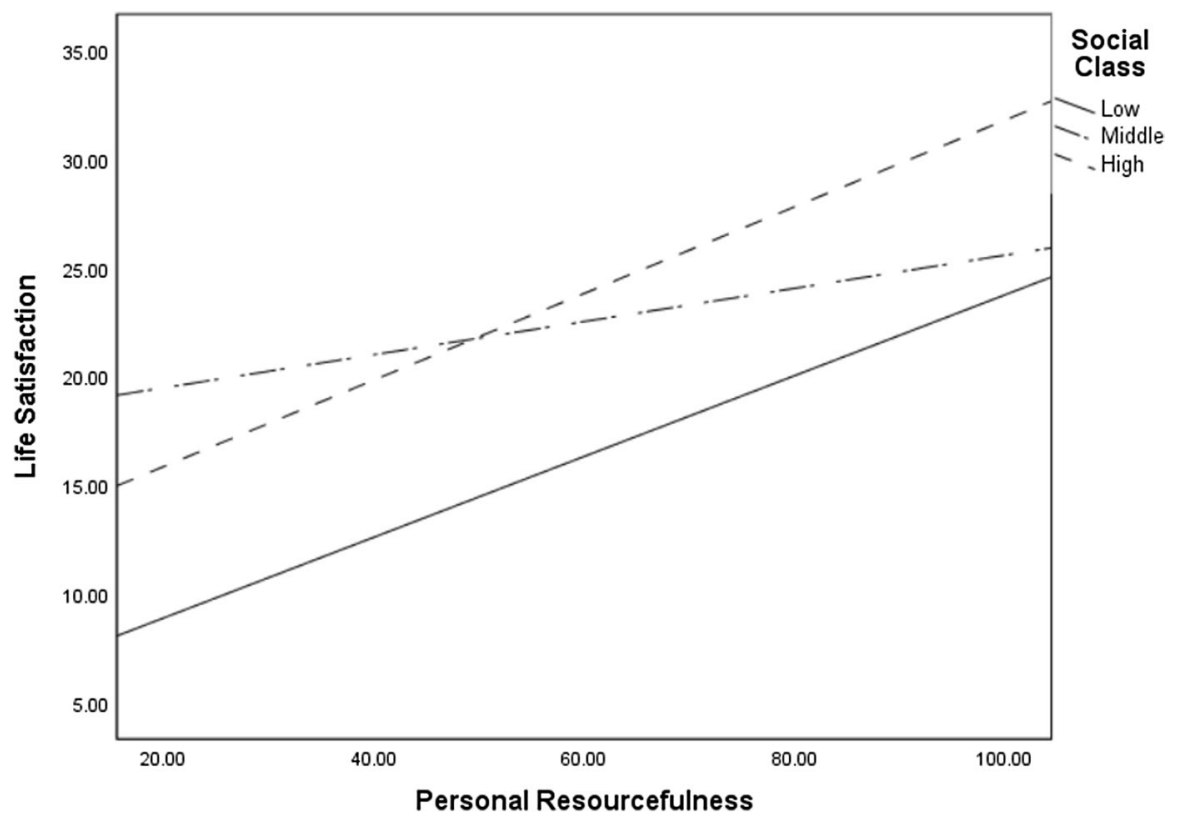

Fig. 2 Subjective social class as a moderator of the relation between social resourcefulness and life satisfaction 
Table 3 Regression analysis examining subjective social class as a moderator of the relations between the positive characteristics and positive emotions

\begin{tabular}{lcccccccccc}
\hline & $\beta$ & $B$ & $S E$ B & $t$ & $p$ & $d f$ & $R$ & $R^{2}$ & $R^{2} \Delta$ & $F$ \\
\hline Step 1 & & & & & $<.001$ & 5 & .76 & .57 & .57 & 101.45 \\
Social Class & .13 & .39 & .11 & 3.53 & $<.001$ & & & & & \\
Optimism & .36 & .36 & .04 & 8.64 & $<.001$ & & & & & \\
Personal Resourcefulness & .16 & .06 & .02 & 3.65 & $<.001$ & & & & & \\
Social Resourcefulness & .16 & .08 & .02 & 4.13 & $<.001$ & & & & \\
Meaning in Life & .25 & .19 & .03 & 5.93 & $<.001$ & & & & & \\
Step 2 & & & & & $<.001$ & 9 & .76 & .57 & .00 & 56.26 \\
Social Class & -.04 & -.11 & .62 & -.18 & .858 & & & & \\
Optimism & .35 & .35 & .04 & 8.08 & $<.001$ & & & & \\
Personal Resourcefulness & .16 & .07 & .02 & 3.65 & $<.001$ & & & & & \\
Social Resourcefulness & .16 & .08 & .02 & 3.87 & $<.001$ & & & & \\
Meaning in Life & .25 & .19 & .03 & 5.74 & $<.001$ & & & & \\
SocialClassXOptimism & -.05 & -.26 & .22 & -1.15 & .250 & & & & & \\
SocialClassXPersonalResourceful & .17 & .01 & .02 & .78 & .435 & & & & & \\
SocialClassXSocialResourceful & -.01 & -.02 & .24 & -.08 & .936 & & & & & \\
SocialClassXMeaninginLife & .01 & .04 & .24 & .16 & .877 & & & & \\
\hline & & & & & & & & & \\
\hline
\end{tabular}

Table 4 Regression analysis examining subjective social class as a moderator of the relations between the positive characteristics and negative emotions

\begin{tabular}{lllllllllll}
\hline & $\beta$ & $B$ & $S E B$ & $t$ & $p$ & $d f$ & $R$ & $R^{2}$ & $R^{2} \Delta$ & $F$ \\
\hline Step 1 & & & & & $<.001$ & 5 & .59 & .35 & .34 & 40.00 \\
Social Class & .01 & .01 & .13 & .08 & .937 & & & & & \\
Optimism & -.47 & -.46 & .05 & -9.12 & $<.001$ & & & & & \\
Personal Resourcefulness & -.06 & -.02 & .02 & -1.12 & .265 & & & & & \\
Social Resourcefulness & .07 & .03 & .02 & 1.36 & .174 & & & & & \\
Meaning in Life & -.16 & -.12 & .04 & -3.13 & .002 & & & & & \\
Step 2 & & & & & $<.001$ & 9 & .59 & .35 & .00 & 22.30 \\
Social Class & .19 & .55 & .76 & .72 & .471 & & & & & \\
Optimism & -.47 & -.46 & .05 & -8.67 & $<.001$ & & & & & \\
Personal Resourcefulness & -.06 & -.03 & .02 & -1.22 & .225 & & & & & \\
Social Resourcefulness & .06 & .03 & .02 & 1.27 & .204 & & & & & \\
Meaning in Life & -.16 & -.12 & .04 & -2.90 & .004 & & & & & \\
SocialClassXOptimism & -.04 & -.18 & .27 & -.67 & .503 & & & & & \\
SocialClassXPersonalResourceful & -.20 & -.02 & .02 & -.75 & .452 & & & & & \\
SocialClassXSocialResourceful & .05 & .28 & .30 & .94 & .347 & & & & & \\
SocialClassXMeaninginLife & .03 & .14 & .30 & .48 & .633 & & & & & \\
\hline
\end{tabular}


to the other middle and upper social class groups. Additionally, as displayed in Fig. 2, all social class groups had a positive relation between personal resourcefulness and life satisfaction. However, the relation between personal resourcefulness and life satisfaction was strongest for the lower and upper social class groups, and relatively weak for the middle-class group. The final model explained $61 \%$ of the variance in life satisfaction.

Tables 3 and 4 display the hierarchical regression analyses of study variables predicting positive affect and negative affect, respectively. In Table 3, subjective social class, optimism, personal resourcefulness, social resourcefulness, and meaning in life significantly predicted positive affect in Step $1, F(5,380)=101.45, p<0.001$, $R^{2}=0.57$. However, none of the interaction terms significantly predicted positive affect when added in Step 2, $F(9,376)=56.26, p<0.001, R^{2}=0.57$. In Table 4, only optimism and meaning in life significantly predicted negative affect in Step 1, F(5, $380)=40.00, p<0.001, R^{2}=0.35$, and none of the interaction terms significantly predicted negative affect in Step $2, F(9,376)=22.30, p<0.001, R^{2}=0.35$. Additionally, neither interaction model contributed additional explained variance beyond that of the predictor variables. The final models explained $57 \%$ of the variance in positive and $35 \%$ of the variance in negative affect.

\section{Discussion}

The purpose of the present study was to investigate whether various positive characteristics had differential relations with subjective well-being based on subjective social status (SSS) identification. According to theory (Yates \& Masten, 2004), both assets and protective factors positively predict well-being (Yates \& Masten, 2004). However, protective factors more strongly predict outcomes for individuals who experience greater vulnerability. We hypothesized that SSS would moderate the relations between positive characteristics and SWB, and that the positive characteristics would specifically be stronger predictors of SWB for lower SSS individuals compared to those who reported higher SSS. Our results suggested that all the positive characteristics significantly predicted life satisfaction, but only the relations among social resourcefulness, personal resourcefulness, and life satisfaction were moderated by SSS. Moreover, we found evidence that all the positive characteristics significantly predicted positive emotions and that optimism and meaning in life predicted negative emotions. However, SSS did not moderate the relations from the positive characteristics to positive or negative emotions.

In support of our hypotheses, we found social resourcefulness was a stronger predictor of life satisfaction for people with lower SSS compared to people with higher SSS. This finding is congruent with past research on the relation between social resourcefulness and well-being in at-risk populations (Rapp et al., 1998). In line with past research on protective factors (Hamby et al., 2018), social resourcefulness might gain its resilience quality for individuals with lower SSS because it may help them mobilize their supportive relationships and other positive external resources (e.g., social support, accessing health services or other prosocial organizations) to increase the likelihood of meeting their basic needs and goals, which in turn lead to 
fulfillment and well-being. However, research replicating and extending these findings with multiple sources of data and longitudinal data is critical to be confident in the results.

Additionally, our hypotheses for the relations among SSS, personal resourcefulness, and life satisfaction were partial supported. Contrary to our hypotheses, personal resourcefulness was not a stronger predictor of life satisfaction for individuals with lower SSS relative to those with higher SSS. Instead, it seemed equally important for both groups but had a weak relation to life satisfaction for individuals in the middle SSS group. Other studies have found similar results (Hamarta, 2009; Zauszniewski, 2016), but our study is the first to investigate the relation between personal resourcefulness and SSS. Personal resourcefulness might be important to lower and upper social class groups for different reasons. For instance, it might be important for lower social class groups because of their constant risk and vulnerability. For upper social class groups, personal resourcefulness might be important because of the individualistic and competitive nature of their economic culture (Fouad \& Brown, 2000), whereas neither of these factors might be as strong for persons among the middle classes. Regardless, given that these results were unexpected and our data were limited in several ways, these interpretations are speculative and future research should further explore the results in greater detail.

Contrary to our hypotheses, SSS did not moderate the relations between any of the positive characteristics and positive or negative emotion, but optimism, meaning in life, social and personal resourcefulness all positively predicted positive emotion, and optimism and meaning in life negatively predicted negative emotion. From the resilience theory framework (Yates \& Masten, 2004), these positive characteristics might be assets. Notably, optimism and meaning in life had the strongest associations to positive and negative affect. These findings are consistent with past research (Andersson, 1996; Zika \& Chamberlain, 1992), and suggest that optimism and meaning in life might be important assets to individuals across the social class spectrum. Again, replication of these results is necessary to feel confident in these statements.

\subsection{Practical Implications}

These findings have potential implications for helping professionals who serve adults from lower social class backgrounds (e.g., psychologists, social workers, mental health counselors, nurses). Our most critical finding suggests that social resourcefulness may be especially important for lower social class groups. Thus, if clinically indicated, clinicians could assess social resourcefulness at intake and use interventions intended to develop and encourage the use of this positive characteristic. Zauszniewski et al. (2007) developed a resourcefulness training with elderly adults that taught when and how to use formal (e.g., health professionals) and informal (i.e., friends and family) sources of external support. These trainings effectively decrease negative affect, stress, and depression, and improve quality of life (Zauszniewski et al., 2007, 2014). Therefore, interventions that target the skills and 
motivation for help-seeking and activation of social supports are options for individuals from lower social classes, if clinically appropriate.

Additionally, our findings that optimism and meaning in life are associated with subjective well-being are also relevant to helping professionals and laypersons. Specifically, these positive characteristics might be beneficial for individuals regardless of their social status. Mental health professionals can help clients increase their optimism by employing the Best Possible Selves intervention (Malouff \& Schutte, 2017) and learned optimism techniques (e.g., cognitive distancing from negative events and linking to positive desired future outcomes; Seligman, 2006). Moreover, there are numerous ways shown to increase meaning in life, including enhancing one's sense of belonging (Lambert et al., 2013), engaging in prosocial behavior (Klein, 2017), and practicing gratitude (Kleiman et al., 2013). Although these interventions are likely beneficial for almost anyone, they may also help to promote happiness and health in economically marginalized populations.

\subsection{Limitations and Future Directions}

Our study had several significant limitations. Chiefly, we used a cross-sectional design with self-report measures to investigate the hypothesized relations among study variables. First, this design creates limitations for disentangling temporal precedence. Resilience is a construct that unfolds overtime (Masten et al., 2009), and the cross-sectional nature of our data can only modestly estimate these relations. In addition, greater subjective well-being my lead participants to report greater subjective social status, rather than vice versa.

Second, our results may have been conflated by common method variance (CMV). In other words, significant relations in our study may be due to systematic measurement error derived from data retrieved from single respondents in a single moment in time, rather than true effects (Podsakoff et al. 2003). Other studies have discussed CMV related to SSS and argued that it is unlikely to be a significant concern (Nobles et al., 2013; Singh-Manoux et al., 2005). In addition, we included several preventative measures against CMV, including having variable scale lengths, different scale anchors, keeping responses anonymous, choosing clear scales, and including reverse coded items (Podsakoff et al. 2003). Regardless, CMV may have biased our results, and it is important to view our findings within context of these limitations and as only a necessary first step in studying these phenomena.

Future resilience research with lower social class groups can address these issues in several ways. First, incorporating multiple methods for measuring study variables beyond perceptual-based measures might help to reduce the likelihood of CMV affecting results (Podsakoff et al. 2003). Moreover, longitudinal designs are likely optimal when studying resilience (Masten et al., 2009) and can help draw temporal precedence among study variables. Considering these limitations, we believe crosssectional research provides valuable preliminary information on potential relationships among study variables and can be used to inform and justify more complex and costly research. 
Other limitations are related to our sample. Namely, our sample was more educated than the population we aimed to estimate - over $56 \%$ indicated possessing a college or professional degree (U.S. Census Bureau, 2019). This potentially decreased the external validity of our results because we made assumptions about the vulnerability and risk experienced by participants who reported lower levels of SSS. Rather, our participants may have had greater access to resources than our target population. Although this is a limitation, we controlled for levels of education in our analyses, and this did not change our results. Moreover, Masten et al. (2009) suggested that lower social class membership does not necessarily place one at risk because aspects of a person's environment might buffer against difficulties related to their social status. Therefore, future studies should use more sophisticated techniques to measure vulnerability in lower social class groups, such as measuring the absence of economic resources, social power, or experiences of classism (Thompson \& Subich, 2006, 2013).

Additionally, our sample was also predominantly White. This limitation decreases the extent to which study findings may generalize to specific racial and ethnic minority groups who identify as having lower social status. This is problematic because race and social class are inextricably intertwined (Fouad \& Brown, 2000), and the range in scores on SSS we observed might be somewhat restricted due to our sample being well-educated and mostly White, which could have further inflated CMV. Future resilience research should intentionally recruit individuals with multiple marginalized identities who might experience greater risk, vulnerability, and variation in SSS than our sample.

Authors' Contributions All authors contributed to the study conception and design. Material preparation, data collection and analysis were performed by Patrick K. Murphy and Blake A. Allan. The first draft of the manuscript was written by Patrick K. Murphy and all authors commented on previous versions of the manuscript. All authors read and approved the final manuscript.

Funding No funds, grants, or other support was received.

Availability of Data Not applicable.

Code Availability Not applicable.

\section{Declarations}

Conflicts of Interest The authors have no relevant financial or non-financial interests to disclose.

Ethics Approval Our study complied with all ethical standards and was approved by Purdue University's Institutional Review Board (IRB \# 1902021680).

Consent to Participate All study data was anonymized. All study participants were informed about the nature of the study and were explicitly informed that their participation was voluntary. Additionally, all participants were explicitly informed that they could terminate their participation in the study at any time.

Consent for Publication All authors approve this manuscript for publication. 


\section{References}

Adler, N. E., Boyce, W. T., Chesney, M. A., Folkman, S., \& Syme, S. L. (1993). Socioeconomic inequalities in health: No easy solution. JAMA, 269(24), 3140-3145. https://doi.org/10.1001/jama. 1993.03500240084031

Adler, N. E., Epel, E. S., Castellazzo, G., \& Ickovics, J. R. (2000). Relationship of subjective and objective social status with psychological and physiological functioning: Preliminary data in healthy White Women. Health Psychology, 19(6), 586-592. https://doi.org/10.1037/0278-6133. 19.6.586

Andersson, G. (1996). The benefits of optimism: A meta-analytic review of the Life Orientation Test. Personality and Individual Differences, 21(5), 719-725. https://doi.org/10.1016/0191-8869(96) 00118-3

Ayed, N., Toner, S., \& Priebe, S. (2019). Conceptualizing resilience in adult mental health literature: A systematic review and narrative synthesis. Psychology and Psychotherapy: Theory, Research and Practice, 92(3), 299-341. https://doi.org/10.1111/papt.12185

Bailey, T. C., Eng, W., Frisch, M. B., \& Snyder, C. R. (2007). Hope and optimism as related to life satisfaction. The Journal of Positive Psychology, 2(3), 168-175. https://doi.org/10.1080/1743976070 1409546

Blustein, D. L. (2006). The psychology of working: A new perspective for career development, counseling, and public policy. Lawrence Erlbaum.

Buhrmester, M., Kwang, T., \& Gosling, S. D. (2011). Amazon's Mechanical Turk: A new source of inexpensive, yet high-quality, data? Perspectives on Psychological Science, 6(1), 3-5. https://doi.org/10. 1037/14805-009

Bullock, H. E. (1995). Class acts: Middle-class responses to the poor. In B. Lott \& D. Maluso (Eds.), The social psychology of interpersonal discrimination (pp. 118-159). Guilford Press.

Carey, R. M., \& Markus, H. R. (2016). Understanding consumer psychology in working-class contexts. Journal of Consumer Psychology, 26, 568-582. https://doi.org/10.1016/j.jcps.2016.08.004

Christopher, J. C., \& Howe, K. L. (2014). Future directions for a more multiculturally competent (and humble) positive psychology. In Perspectives on the intersection of multiculturalism and positive psychology (pp. 253-266). Springer, Dordrecht.

Crosnoe, R., Mistry, R. S., \& Elder, G. H., Jr. (2002). Economic disadvantage, family dynamics, and adolescent enrollment in higher education. Journal of Marriage and Family, 64(3), 690-702. https:// doi.org/10.1111/j.1741-3737.2002.00690.x

Cundiff, J. M., Smith, T. W., Uchino, B. N., \& Berg, C. A. (2013). Subjective social status: Construct validity and associations with psychosocial vulnerability and self-rated health. International Journal of Behavioral Medicine, 20(1), 148-158. https://doi.org/10.1007/s12529-011-9206-1

Destin, M. (2019). Socioeconomic mobility, identity, and health: Experiences that influence immunology and implications for intervention. American Psychologist, 74(2), 207-217. https://doi.org/10.1037/ amp0000297

Diemer, M. A., Mistry, R. S., Wadsworth, M. E., López, I., \& Reimers, F. (2013). Best practices in conceptualizing and measuring social class in psychological research. Analyses of Social Issues and Public Policy, 13(1), 77-113. https://doi.org/10.1111/asap.12001

Diener, E. (2000). Subjective well-being: The science of happiness and a proposal for a national index. American Psychologist, 55(1), 34-43. https://doi.org/10.1037/0003-066X.55.1.34

Diener, E., Emmons, R. A., Larsen, R. J., \& Griffin, S. (1985). The Satisfaction with Life Scale. Journal of Personality Assessment, 49, 71-75. https://doi.org/10.1207/s15327752jpa4901_13

Diener, E., Wirtz, D., Tov, W., Kim-Prieto, C., Choi, D., Oishi, S., \& Biswas-Diener, R. (2010). New well-being measures: Short scales to assess flourishing and positive and negative feelings. Social Indicators Research, 97(2), 143-156. https://doi.org/10.1007/s11205-009-9493-y

Fouad, N. A., \& Brown, M. T. (2000). Role of race and social class in development: Implications for counseling psychology. In S. D. Brown \& R. W. Lent (Eds.), Handbook of counseling psychology., 3rd ed. (pp. 379-408). John Wiley \& Sons, Inc.

Frankenhuis, W. E., \& Nettle, D. (2020). The Strengths of People in Poverty. Current Directions in Psychological Science, 29(1), 16-21. 10.1177\%2F0963721419881154

Franzini, L., \& Fernandez-Esquer, M. E. (2006). The association of subjective social status and health in low-income Mexican-origin individuals in Texas. Social Science \& Medicine, 63(3), 788-804. https://doi.org/10.1016/j.socscimed.2006.01.009 
Garza, J. R., Glenn, B. A., Mistry, R. S., Ponce, N. A., \& Zimmerman, F. J. (2017). Subjective social status and self-reported health among US-born and immigrant Latinos. Journal of Immigrant and Minority Health, 19(1), 108-119. https://doi.org/10.1007/s10903-016-0346-X

Hamarta, E. (2009). A prediction of self-esteem and life satisfaction by social problem solving. Social Behavior and Personality: An International Journal, 37(1), 73-82. https://doi.org/10.2224/sbp. 2009.37.1.73

Hamby, S., Grych, J., \& Banyard, V. (2018). Resilience portfolios and poly-strengths: Identifying protective factors associated with thriving after adversity. Psychology of Violence, 8(2), 172-183. https:// doi.org/10.1037/vio0000135

Hoaglin, D. C., \& Iglewicz, B. (1987). Fine-tuning some resistant rules for outlier labeling. Journal of the American Statistical Association, 82(400), 1147-1149. https://doi.org/10.1080/01621459.1987. 10478551

Kleiman, E. M., Adams, L. M., Kashdan, T. B., \& Riskind, J. H. (2013). Gratitude and grit indirectly reduce risk of suicidal ideations by enhancing meaning in life: Evidence for a mediated moderation model. Journal of Research in Personality, 47(5), 539-546. https://doi.org/10.1016/j.jrp.2013.04. 007

Klein, N. (2017). Prosocial behavior increases perceptions of meaning in life. The Journal of Positive Psychology, 12(4), 354-361. https://doi.org/10.1080/17439760.2016.1209541

Lachman, M. E., \& Weaver, S. L. (1998). The sense of control as a moderator of social class differences in health and well-being. Journal of Personality and Social Psychology, 74(3), 763-773.

Lambert, N. M., Stillman, T. F., Hicks, J. A., Kamble, S., Baumeister, R. F., \& Fincham, F. D. (2013). To belong is to matter: Sense of belonging enhances meaning in life. Personality and Social Psychology Bulletin, 39(11), 1418-1427. https://doi.org/10.1177/2F0146167213499186

Liu, W. M. (2011). Social class and classism in the helping professions: Research, theory, and practice. Sage.

Liu, W. M., Soleck, G., Hopps, J., Dunston, K., \& Pickett, T., Jr. (2004). A new framework to understand social class in counseling: The social class worldview model and modern classism theory. Journal of Multicultural Counseling and Development, 32(2), 95-122. https://doi.org/10.1002/j.2161-1912. 2004.tb00364.x

Lott, B., \& Bullock, H. E. (2007). Psychology and economic injustice: Personal, professional, and political intersections. American Psychological Association.

Ma, J., Pender, M., \& Welch, M. (2016). Education Pays 2016: The Benefits of Higher Education for Individuals and Society. Trends in Higher Education Series. College Board.

Machell, K. A., Kashdan, T. B., Short, J. L., \& Nezlek, J. B. (2015). Relationships between meaning in life, social and achievement events, and positive and negative affect in daily life. Journal of Personality, 83(3), 287-298. https://doi.org/10.1111/jopy.12103

Malouff, J. M., \& Schutte, N. S. (2017). Can psychological interventions increase optimism? A metaanalysis. The Journal of Positive Psychology, 12(6), 594-604. https://doi.org/10.1080/17439760. 2016.1221122

Masten, A. S. (2007). Resilience in developing systems: Progress and promise as the fourth wave rises. Development and Psychopathology, 19(3), 921-930. https://doi.org/10.1017/S0954579407000442

Masten, A. S., \& Obradović, J. (2006). Competence and resilience in development. Annals of the New York Academy of Sciences, 1094(1), 13-27. https://doi.org/10.1196/annals.1376.003

Masten, A. S., Cutuli, J. J., Herbers, J. E., \& Reed, M. J. (2009). Resilience in development. In S. J. Lopez \& C. R. Snyder (Eds.), The Oxford handbook of positive psychology (2nd ed., pp. 117-131). Oxford University Press.

Meyer, P., \& Mueser, K. (2011). Resiliency in individuals with serious mental illness. In S. M. Southwick, B. T. Litz, D. Charney, \& M. J. Friedman (Eds.), Resilience and mental health: Challenges across the lifespan (pp. 276-288). Cambridge University Press.

Nicholson, J. (2014). Supporting mothers living with mental illness in recovery. In N. Benders-Hadi \& M. E. Barber (Eds.), Motherhood, mental illness and recovery: Stories of hope (pp. 3-18). Springer.

Nobles, J., Weintraub, M. R., \& Adler, N. E. (2013). Subjective socioeconomic status and health: Relationships reconsidered. Social Science \& Medicine, 82, 58-66. https://doi.org/10.1016/j.socscimed. 2013.01.021

Okech, D., Howard, W. J., Mauldin, T., Mimura, Y., \& Kim, J. (2012). The effects of economic pressure on the resilience and strengths of individuals living in extreme poverty. Journal of Poverty, 16(4), 429-446. https://doi.org/10.1080/10875549.2012.720659 
Operario, D., Adler, N. E., \& Williams, D. R. (2004). Subjective social status: Reliability and predictive utility for global health. Psychology \& Health, 19(2), 237-246. https://doi.org/10.1080/0887044031 0001638098

Ostrove, J. M., Adler, N. E., Kuppermann, M., \& Washington, A. E. (2000). Objective and subjective assessments of socioeconomic status and their relationship to self-rated health in an ethnically diverse sample of pregnant women. Health Psychology, 19(6), 613-618. https://doi.org/10.1037/ 0278-6133.19.6.613

Pedrotti, J. T., \& Edwards, L. M. (2017). Cultural context in positive psychology: History, research, and opportunities for growth. In M. A. Warren \& S. I. Donaldson (Eds.), Scientific advances in positive psychology. (pp. 257-287). Santa Barbara, CA: Praeger/ABC-CLIO.

Pedrotti, J. T. (2013). Positive psychology, social class, and counseling. The Oxford handbook of social class in counseling, 131-143.

Podsakoff, P. M., MacKenzie, S. B., Lee, J. Y., \& Podsakoff, N. P. (2003). Common method biases in behavioral research: A critical review of the literature and recommended remedies. Journal of Applied Psychology, 88(5), 879-903. https://doi.org/10.1037/0021-9010.88.5.879

Rapp, S. R., Shumaker, S., Schmidt, S., Naughton, M., \& Anderson, R. (1998). Social resourcefulness: Its relationship to social support and wellbeing among caregivers of dementia victims. Aging \& Mental Health, 2(1), 40-48. https://doi.org/10.1080/13607869856920

Reed, D. J. (2016). Coping with occupational stress: The role of optimism and coping flexibility. Psychology Research and Behavior Management, 9, 71-79. https://doi.org/10.2147/PRBM.S97595

Sabina, C., \& Banyard, V. (2015). Moving toward well-being: The role of protective factors in violence research. Psychology of Violence, 5(4), 337-342. https://doi.org/10.1037/a0039686

Scheier, M. F., Carver, C. S., \& Bridges, M. W. (1994). Distinguishing optimism from neuroticism (and trait anxiety, self-mastery, and self-esteem): A reevaluation of the Life Orientation Test. Journal of Personality and Social Psychology, 67(6), 1063-1078.

Seligman, M. E. (2006). Learned optimism: How to change your mind and your life. Vintage Books.

Shaw, M. D. D., \& Smith, G. D. (2006). Poverty, social exclusion, and minorities. In M. Marmot \& R. G. Wilkinson (Eds.), Social Determinants of Health (2nd ed., pp. 196-223). Oxford University Press.

Singh-Manoux, A., Adler, N. E., \& Marmot, M. G. (2003). Subjective social status: Its determinants and its association with measures of ill-health in the Whitehall II study. Social Science \& Medicine, 56(6), 1321-1333. https://doi.org/10.1016/S0277-9536(02)00131-4

Singh-Manoux, A., Marmot, M. G., \& Adler, N. E. (2005). Does subjective social status predict health and change in health status better than objective status? Psychosomatic Medicine, 67(6), 855-861. https://doi.org/10.1097/01.psy.0000188434.52941.a0

Sirin, S. R. (2005). Socioeconomic status and academic achievement: A meta-analytic review of research. Review of Educational Research, 75(3), 417-453. https://doi.org/10.3102/2F00346543075003417

Sprouse, J. (2011). A validation of Amazon Mechanical Turk for the collection of acceptability judgments in linguistic theory. Behavior Research Methods, 43(1), 155-167. https://doi.org/10.3758/ s13428-010-0039-7

Steger, M. F., Frazier, P., Oishi, S., \& Kaler, M. (2006). The meaning in life questionnaire: Assessing the presence of and search for meaning in life. Journal of Counseling Psychology, 53(1), 80-93. https:// doi.org/10.1037/0022-0167.53.1.80

Subramanyam, M., Kawachi, I., Berkman, L., \& Subramanian, S. V. (2009). Relative deprivation in income and self-rated health in the United States. Social Science \& Medicine, 69(3), 327-334. https://doi.org/10.1016/j.socscimed.2009.06.008

Thompson, M. N., \& Subich, L. M. (2006). The relation of social status to the career decision-making process. Journal of Vocational Behavior, 69(2), 289-301. https://doi.org/10.1016/j.jvb.2006.04.008

Thompson, M. N., \& Subich, L. M. (2013). Development and exploration of the experiences with classism scale. Journal of Career Assessment, 21(1), 139-158. https://doi.org/10.1177/2F10690727 12450494

U.S. Census Bureau (2019). QuickFacts: United States. Retrieved from https://www.census.gov/quick facts/fact/table/US/PST045219\#

Yates, T. M., \& Masten, A. S. (2004). Fostering the future: Resilience theory and the practice of positive psychology. In P. A. Linley \& S. Joseph (Eds.), Positive psychology in practice (pp. 521-539). John Wiley \& Sons Inc.

Yngwe, M. A., Fritzell, J., Lundberg, O., Diderichsen, F., \& Burström, B. (2003). Exploring relative deprivation: Is social comparison a mechanism in the relation between income and health? Social Science \& Medicine, 57(8), 1463-1473. https://doi.org/10.1016/S0277-9536(02)00541-5 
Yu, S., \& Blader, S. L. (2020). Why does social class affect subjective well-being? The role of status and power. Personality and Social Psychology Bulletin, 46(3), 331-348. https://doi.org/10.1177/2F014 6167219853841

Zauszniewski, J. A. (2016). Resourcefulness. Western Journal of Nursing Research, 38(12), 1551-1553. https://doi.org/10.1177/2F0193945916665079

Zauszniewski, J. A., Chien-Yu, L., \& Tithiphontumrong, S. (2006). Development and testing of the resourcefulness scale for older adults. Journal of Nursing Measurement, 14(1), 57-68. https://doi. org/10.1891/jnum.14.1.57

Zauszniewski, J. A., Bekhet, A. K., Lai, C. Y., McDonald, P. E., \& Musil, C. M. (2007). Effects of teaching resourcefulness and acceptance on affect, behavior, and cognition of chronically ill elders. Issues in Mental Health Nursing, 28(6), 575-592. https://doi.org/10.1080/01612840701354547

Zauszniewski, J. A., Musil, C. M., Burant, C. J., \& Au, T. Y. (2014). Resourcefulness training for grandmothers: Preliminary evidence of effectiveness. Research in Nursing \& Health, 37(1), 42-52. https://doi.org/10.1002/nur.21574

Zika, S., \& Chamberlain, K. (1992). On the relation between meaning in life and psychological wellbeing. British Journal of Psychology, 83(1), 133-145. https://doi.org/10.1111/j.2044-8295.1992. tb02429.x

Publisher's Note Springer Nature remains neutral with regard to jurisdictional claims in published maps and institutional affiliations. 